\title{
CIENTIFICISMO ESPIRITUAL: LA OBRA DE ARTURO ALDUNATE PHILIPS EN LA DISCUSIÓN SOBRE CIENCIA Y DESARROLLO
}

\author{
SPIRITUAL SCIENTISM: THE WORK OF ARTURO ALDUNATE PHILIPS \\ IN THE DISCUSSION ON SCIENCE AND DEVELOPMENT
}

\author{
Christian Álvarez-Rojas* \\ Universidad de Santiago de Chile \\ Santiago-Chile \\ Recibido diciembre de 2019/Received December, 2019 \\ Aceptado junio de 2020/Accepted June, 2020
}

\begin{abstract}
RESUMEN
El cientificismo ha sido señalado frecuentemente como una ideología equivalente a la modernidad y el colonialismo. El objetivo de este artículo es examinar este concepto bajo el enfoque del Pensamiento Latinoamericano, y definirlo como un dispositivo usado para reforzar conjuntos de ideas de mayor alcance. Para ello expondré el pensamiento de Arturo Aldunate Philips contenido en su obra de divulgación científica como un cientificismo espiritual, enfrentado a la discusión acerca del rol de la ciencia en el desarrollo en Chile y América Latina.
\end{abstract}

Palabras Clave: Arturo Aldunate Philips, cientificismo, Pensamiento Latinoamericano, ciencia y desarrollo, espiritualidad.

\section{ABSTRACT}

Scientism has been frequently pointed out as an ideology equivalent to modernity and colonialism. This article aims to study this concept under the approach of Latin American Thought, and define it as a device used to reinforce sets of broader ideas. For that purpose, I will explain the thought of Arturo Aldunate Phillips contained in his popular science work as a spiritual scientism, faced with the discussion about the role of science in the development in Chile and Latin America.

Key Words: Arturo Aldunate Philips, scientism, Latin American Thought, Science and Development, spirituality.

\section{INTRODUCCIÓN}

El cientificismo es un concepto que advierte un uso polémico de los conocimientos y métodos de las ciencias naturales hacia disciplinas o ámbitos del saber, al menos en apariencia, diferentes. Para el pensamiento latinoamericano ha sido un problema especialmente visible debido a la realidad de la historia colonial, así como la inclusión periférica y subordinada en el orden global. El cientificismo, por tanto, requiere la mayor clarificación posible, para que no sea solo un adjetivo crítico o elogioso de una proposición, por justificada que esta sea, sino además un foco de análisis respecto de las discusiones de la relación entre las ciencias y otras áreas del conocimiento y la sociedad en general. Para ello expondré una clasificación del cientificismo desde los estudios de las ideas, analizando luego el pensamiento del ingeniero y ensayista chileno Arturo Aldunate Philips. En este análisis, se espera demostrar que el cientificismo es un dispositivo que puede adosarse a conjuntos de ideas en apariencia lejanas a la reflexión pertinente a las ciencias, como

\footnotetext{
* Doctor (c) en Estudios Americanos, Instituto de Estudios Avanzados, Universidad de Santiago de Chile. Becario Doctorado Nacional ANID/CONICYT 21160875 / Corresponding author: christian.alvarez.r@usach.cl
} 
en este caso, a la espiritualidad y un pensamiento político conservador.

\section{ANTECEDENTESDEL CIENTIFICISMO}

Las primeras menciones del cientificismo aparecen en el siglo XIX buscando describir de forma peyorativa el uso de los resultados y métodos de las ciencias para sostener posiciones fuera de su alcance disciplinar. La primera mención, registrada por Peter Schöttler (2017) ocurre en la década de 1870 como crítica al movimiento sectario Christian Science, y pronto fue tomado por Charles Renouvier en 1876 para exponer las arbitrariedades del positivismo (Raynaud, 2017). A pesar de la motivación crítica e incluso moralizante de los primeros usos del concepto "cientificismo", puede considerarse como descriptivo del fenómeno cultural resultante del éxito y consolidación de las ciencias naturales como actividad autónoma y específica, hecho también identificable con el origen del concepto "científico" (scientist), acuñado en 1833 por William Whewell para englobar a los especialistas en disciplinas específicas derivadas de la filosofía natural (Wootton, 2015). El cientificismo, por esta razón, da cuenta de la tensión entre el conocimiento y sus usos, pudiendo encontrarse en momentos históricos anteriores y posteriores al específico de su origen. De esta forma, Luis Villoro considera que " $[\mathrm{e}] 1$ cientificismo, es decir, la tendencia a medir toda forma de justificación racional por el rasero de la racionalidad científica, llegará a ser un rasgo del pensamiento" (1992, p. 122).

El concepto de cientificismo ha tenido un lugar relevante en el pensamiento latinoamericano, especialmente por su vinculación a los procesos de colonización y modernización que han situado a Nuestramérica como una región periférica. Con esta perspectiva de análisis podemos leer al filósofo Enrique Dussel plantear en su obra Filosofía de la Liberación que se trata de "una ideología corriente en el centro [...] aunque menos ingenua que la cotidianidad del hombre de la calle, tiene mayor peligrosidad, por cuanto da los instrumentos necesarios para que el poder del centro se ejerza sobre la periferia" (p. 47). Para la historiadora Ana María Bidegaín constituye una ideología y "un elemento cultural importantísimo para la dominación del continente americano" y, en un tono similar, la filósofa Adriana Arpini plantea que, junto con el etnocentrismo, el racialismo y el nacionalismo, es una "figura ideológica" (en su sentido de falsa conciencia) donde se plantea la dicotomía "nosotros/los otros". No será el objetivo de este artículo cuestionar los argumentos que sostienen estas posiciones, pero sí extraer de ellos una constatación: en primer lugar, el cientificismo se analiza según sus consecuencias externas y no por alguna formulación intrínseca, y segundo, se asume una emanación desde el centro que, o se ha padecido de forma indefensa, o se ha replicado según los mismos intereses y métodos originales. Si el cientificismo ha sido un mecanismo responsable de nuestra condición periférica, bien valdría la pena detenerse en sus fundamentos y en las diferencias y matices producidos en la misma periferia, tomando partido por la afirmación de un pensamiento latinoamericano.

Respecto del funcionamiento del cientificismo, tomaremos como ejemplo, tanto por su alcance conceptual como por su importancia en el canon latinoamericano, las desarrolladas por Luis Villoro y Mario Bunge. Para el filósofo mexicano, siguiendo la fenomenología de Husserl, el cientificismo olvida "la dimensión personal del conocimiento, conduce a una deshumanización del saber [...] Pretende reducir todo conocimiento a un saber objetivo, del que está ausente cualquier postulación de valores". Esto abre la puerta para un uso ideológico, pues oculta los fines que puede tener la propia investigación científica. Para Mario Bunge, en cambio, el cientificismo se trata de "la tesis de que la mejor manera de encarar los problemas del conocimiento es adoptar el enfoque científico" (2017, p. 13). El cientificismo sería la "matriz filosófica de la investigación científica" caracterizado, entre otras cosas, por el realismo metafísico (existe una realidad objetiva), el optimismo epistémico (se puede obtener conocimiento de esa realidad) y factores sociológicos expuestos por Robert Merton: el desinterés, la universalidad, el comunismo gnoseológico y el escepticismo organizado. La oposición al cientificismo sería más bien un resabio de filosofías idealistas puestas al servicio de fines ideológicos contrailustrados, representados por la aversión a la investigación de fenómenos naturales o sociales en favor de explicaciones dogmáticas.

La diversidad de posiciones que es posible reconocer en torno a un concepto aparentemente consensuado como "cientificismo" puede ser catalogada en los términos que ofrece el filósofo Massimo Pigliucci (2017), quien distingue tres usos no neutrales vigentes: la connotación negativa razonable, como las propuestas por Villoro, Bidegaín o Arpini; 
an increasingly pernicious "unreasonable negative connotation", a simplistic use of "scientism” as an epithet to be hurled at ideas one doesn't like, in lieu of an argument $^{1}$ (p. 188), como las posiciones que critica Bunge; y una connotación "reciente y emergente" de parte de científicos y filósofos que argumentan que there is "no such thing" as an exaggerated trust in the efficacy of the methods of natural science applied to all áreas of investigation ${ }^{2}$ (Ibid.), como el argumento del propio Bunge y, según la hipótesis que se defenderá en este artículo, la de Aldunate Philips.

La clasificación propuesta por Pigliucci, si bien acierta en reconocer una variedad de uso respecto al concepto de cientificismo, aún permite que en sus opciones puedan encasillarse como similares posiciones que todavía difieren en sus fundamentos, métodos y objetivos, dificultando, de paso, la homogeneidad y continuidad que el cientificismo tendría en América Latina respecto de su origen europeo. Por ello se hace necesario, para efectos de este trabajo, delimitar aún más la clasificación del cientificismo apelando a un criterio descriptivo y enfocado en sus componentes intrínsecos a un nivel tanto epistémico como sociológico.

En este punto, resulta útil revisar el problema bajo el lente de los estudios eidéticos ${ }^{3}$ y la clasificación de entidades eidéticas propuesta por Eduardo Devés. El análisis de las ideas requiere un modelo para clasificarlas y así comprender sus relaciones, ya sea de dependencia, confrontación, derivación o intercambio. Las ideas tienen funciones distintas: dar sentido, explicar la realidad, motivar un cambio social, justificar un orden vigente; y pueden agruparse con mayor o menor nivel de extensión, ya sea conformando ideologías, programas de investigación o enfoques puntuales. Según la clasificación propuesta en Estudios Eidéticos (Devés y Kozel, 2017), consideraré la clasificación de identidades eidéticas según géneros ${ }^{4}$, donde es posible identificar sistemas (ideologías, sistemas filosóficos, teologías), artefactos (manuales o instrucciones sin pretensiones holísticas) y dispositivos. En el caso particular de los dispositivos, se trata de ideas que, por sí solas, no implican explicaciones ni modificaciones de largo alcance, sino más bien se adosan a sistemas o artefactos para focalizar y dar énfasis. Los dispositivos son:

[E]ntidades de menor complejidad que los sistemas, que se agregan a ellos para potenciar alguna de sus dimensiones" (p. 96) Dicho de otro modo, se trata de un conjunto de ideas articuladas sobre la base de una noción fundamental, que no alcanza a constituir un sistema eidético por sus pequeñas dimensiones, en términos de no contemplar afanes holísticos, y que puede articularse a otras entidades, especialmente a sistemas, para mejorar su funcionamiento. Se trata de un conjunto simple de ideas focalizado en alguna dimensión específica, lo cual otorga al sistema eidético preexistente capacidades con las cuales no contaba (pp. 96-7).

Ejemplos de dispositivos eidéticos en el modelo acá mencionado serían el feminismo, la negritud o el nacionalismo, "porque si bien pueden combinarse con algunas [ideologías] no permiten organizar el quehacer de la polis por sí solas [...] Feminismo, negritud y nacionalismo diría que son más bien dispositivos eidéticos, pues se adhieren a cualquier ideología" (p. 112). Para el caso del feminismo, la existencia de vertientes marxistas, anarquistas, liberales (de Miguel, 2000), católicas (Blasco, 2006) e islámicas (Badran, 2009), entre otras, sugiere que la clasificación de dispositivo eidético ofrece un marco fructífero de análisis. En cuanto al cientificismo, las definiciones revisadas aluden de forma recurrente al uso ya sea como problema principal o posibilidad. El cientificismo no implica solamente una concepción determinada del valor de las ciencias, sino que es, al menos como propuesta, la puesta en práctica de esta concepción en campos externos del conocimiento. Con esta comprensión, la caracterización del cientificismo hecha por pensadores y pensadoras cercanos al liberacionismo no es falsa, pues describe un uso histórico de este dispositivo, pero sí es incompleta, en tanto no considera el cientificismo adherido a sistemas eidéticos distintos a los del proceso colonial, por ser posteriores (como el marxismo) o por ser locales (como los nacionalismos locales); ni en funciones potencialmente liberadoras; ni en relación con factores no eidéticos, como las propiedades constitutivas de los ecosistemas intelectuales de Nuestramérica.

Como se ha adelantado, la exposición del pensamiento de Arturo Aldunate Philips tendrá por objetivo la presentación de un cientificismo que también es arielista, es decir, un cientificismo adosado al proyecto filosófico-cultural de José Rodó de identificar a América Latina con un desarrollo 
intelectual y espiritual como rasgo característico, y que para el caso particular chileno, estará mediado por el nacionalismo como oposición al marxismo en tanto filosofía materialista e igualitarista. La exposición de su obra, prolífica, aunque también reiterativa según descripción e intención del propio autor, buscará identificar las premisas que subyacen a su exposición de datos y teorías científicas, y que serán las que orienten su sentido. Siguiendo la propuesta del filósofo Roberto Unger y el físico Lee Smolin, podemos leer las obras de divulgación científica como "filosofía natural", reivindicando un término en apariencia anacrónico:

\section{Today, natural philosophy has not disappeared completely. It lives under disguise. Scientists write popular books, for the general educated public, professing to make their ideas about the science that they practice accessible to non-scientists. They use these books to speculate about the larger meaning of their discoveries for our understanding of the universe and of our place within it [...] The popularizing books have become a secret form of the vanished genre, a crypto natural philosophy $(2014, \text { p. } 82)^{5}$.}

Aun cuando Aldunate no haya sido un científico, entendido como investigador y productor de conocimientos, su formación de ingeniero le permitía comprender los modelos matemáticos de teorías físicas y cosmológicas, proponiéndose luego a sí mismo como intérprete de un sentido de mayor alcance. La filosofía natural intenta distinguir los descubrimientos científicos de sus interpretaciones: The interpretation is regularly influenced by metaphysical preconceptions, especially supra-empirical ontologies - views of the kinds of things that there are in the domain addressed by the science. Such views form an unavoidable part of scientific theorizing (p. 76) ${ }^{6}$. Estas lecturas "de segundo orden" podrán ser usadas como argumento para influir en el destino y orientación de programas de investigación, ya sea dentro de las comunidades científicas, o desde el resto de la sociedad respecto de aquellas, como la discusión del rol de las ciencias en la educación o el desarrollo. El término "filosofía natural", en este sentido, describe más una vocación e intención todavía presente como resabio metafísico de algunas obras dedicadas a la ciencia, más que un tipo definido, sistemático y académico de filosofía, y permite una aproximación a la obra de Arturo
Aldunate que facilite el énfasis en aquellas ideas subyacentes a la exposición divulgativa de teorías y problemas científicos. La filosofía natural será, entonces, un tipo de enfoque en la popularización de la ciencia susceptible de ser encontrado y categorizado según las entidades eidéticas que contenga $\mathrm{y}$ a las que se refiera.

\section{LA CIENCIA COMO CAMINO ESPIRITUAL DE DESARROLLO}

Arturo Aldunate Philips nació el 9 de febrero de 1902 en Santiago, y murió en julio de 1985 en la misma ciudad. A los 19 años intentó iniciar una carrera como poeta con la publicación de su libro Era una sirena, pero la mala recepción de la crítica le hizo abandonar esta vocación. En 1921 ingresa a la Compañía de Electricidad, posteriormente Chilectra, en la que permanecerá hasta su jubilación, llegando a ser director (Aldunate, E., 1981). En paralelo a su actividad profesional, se desempeña como académico, entre 1935 y 1940 en la Pontificia Universidad Católica de Chile, y entre 1941 y 1970 en la Universidad de Chile, siendo el ejercicio en esta última casa de estudios relevante pues ahí impartió, desde 1960, los cursos "Introducción a la cibernética" y "Humanismo científico" (Díaz, M. A. 1987, p. 972), que dieron forma e impulso a la producción ensayística que se revisará en este artículo, y que justificó el que en 1976 recibiera el Premio Nacional de Literatura.

Su primera publicación en esta línea es $A l$ encuentro del hombre, publicado en 1953 en Buenos Aires. De entrada, como epígrafe, Aldunate da cuenta de una primera filiación eidética ${ }^{7}$ al citar al Ariel de José Enrique Rodó:

Ariel es la razón y el sentimiento superior, Ariel es el sublime instinto de perfectibilidad, por cuya virtud se magnifica y convierte en centro de las cosas la arcilla humana, a la que vive vinculada su luz.

Ariel, genio del aire, representa, en el simbolismo de la obra de Shakespeare, la parte noble y alada del espíritu. Ariel es el imperio de la razón y el sentimiento sobre los bajos estímulos de la irracionalidad; es el entusiasmo generoso, el móvil alto y desinteresado en la acción, la espiritualidad de la cultura, la vivacidad y la gracia de la inteligencia -el término ideal a que asciende la selección humana-, rectificando en el hombre superior los tenaces vestigios de Calibán, símbolo de 
sensualidad y torpeza, con el cincel perseverante de la vida (cit. en p. 13).

Aldunate buscará en su obra llevar a cabo la misión arielista, asumiendo a las ciencias como aquel instinto sublime, en tanto sus conocimientos no son simplemente un repositorio de innovaciones técnicas, sino que, ante todo, son un camino de autoconocimiento que llevarán al ser humano a un reencuentro con su Creador. La identificación con Ariel implica también el reconocerse como latinoamericano, asignándole a esta condición periférica un sentido de urgencia para su obra de divulgación científica, la que busca responder al "anhelo de saber del hombre de nuestra América, que, en todos sus niveles sociales muestra una incontenible ambición por seguir, aunque sea de lejos, el sorprendente progreso de la ciencia" (Aldunate, 1970, p. 13). La instrumentalización calibanesca de las ciencias, propia del norte anglosajón, resulta entonces ser un riesgo que debe evitarse, pues resultaría en una tergiversación de los fines que el autor considera últimos para el conocimiento:

El mal empleo de la máquina, esta magnífica creación del genio humano, ha levantado un erróneo concepto de la vida y está induciendo a la familia terrestre a falacias y equivocaciones que pueden demorar su evolución y la llegada de una época más justa y más placentera. Sin embargo, tenemos fe en que esta etapa será superada y que en las conquistas científicas y técnicas no opondrán, en definitiva, y por el contrario, obstáculo en el camino (p. 15).

El énfasis en una concepción utilitaria de las ciencias tiene, por tanto, alcances existenciales: "[1]a ilusoria posibilidad, entrevista por algunos durante el pasado siglo, de encontrar la razón de ser de todo en el estrecho marco de la materia, produjo un desencanto que engendró la fría, oscura y estéril filosofía materialista" (Ibid.). Pero además, existe un riesgo social, ya que se invisibiliza el proceso de producción del conocimiento, que para Aldunate sigue, en parte, el modelo de la teoría heroica del avance científico (Merton, 1979), la que explica la génesis y desarrollo de las ciencias "centradas en hombres geniales" (p. 337) y "a través de una especie de partenogénesis en la cual aparentemente no necesitaron colaboradores" (p. 298). Las ciencias demostrarían implícitamente un orden social y moral idóneo que el instrumentalismo ocultaría:
[C]omo el orangután de la selva, que trepado a un árbol coge de un manotazo el fruto exquisito que creó la sabiduría de Dios, sin pensar en su misterio; así, el nuevo dominador, el "ciudadano", vive entre las maravillas creadas, mal aprovecha de los prodigios puestos a su alcance, sin asombro ni agradecimiento. $\mathrm{Ni}$ siquiera sabe que todo lo que él goza o destruye es el producto del genio de otros, los menos, los desconocidos magos del cerebro que, a través de días y noches y años como afiebradas hormigas fueron adentrándose en la soledad de cabalísticos laboratorios en la búsqueda de mundos infinitos donde se encontraban los gérmenes vitales de todo lo que él disfruta. Porque, y resulta extraño y sorprendente pensarlo, bastaría exterminar algunos centros científicos del mundo, eliminar una corta élite de sabios, pensadores y técnicos, para que todo el progreso de las matemáticas, de la físicoquímica, de la biología y de la mecánica que ha hecho posible nuestro avance, fuera aventado y quedaran las masas ignaras, como niños sin padre, teniendo en sus manos prodigiosos juguetes que no saben hacer funcionar, pero sí destruir (Aldunate, 1953, p. 26).

Aun considerando la función metafórica, resulta interesante la identificación de los científicos con "magos" en "cabalísticos laboratorios". Entendiendo la magia no como una violación de las leyes naturales, como sí serían los milagros, sino como una manifestación misteriosa de estas (Thorndike, 1905) cuyo acceso está limitado a una minoría separada del común. En la monografía publicada en 1956 titulada Alberto Einstein. El hombre y el filósofo, Aldunate reitera este concepto, enfatizando no tanto el posible contenido de verdad de las teorías propuestas por el físico alemán, sino especialmente una interpretación moral de su obra:

Pasarán largos años, tal vez centenas, antes de que la humanidad llegue a adoptar la actitud de amor que las enseñanzas de Einstein le señalan; el maestro seguirá, para la mayoría, siendo el mago de la relatividad, el incomprensible y misterioso manejador de ecuaciones y símbolos que... tal vez, puedan ser verdaderos... Pero las proyecciones que sobre la Filosofía y la posición de ser ante la vida [...] solo irán siendo comprendidas por el hombre gregario, lentamente [...] su espíritu gigante seguirá impulsando al hombre hacia la altura y lo que su cerebro prodigioso alcanzó a expresar quedará incorporado al acervo de las fuerzas 
que ayudan al homo sapiens en su camino de perfección (p. 36).

Esta asociación entre la práctica científica, especialmente a un nivel sobresaliente, y un valor moral, se reafirma en las reseñas biográficas que Aldunate presenta de los naturalistas Andrés Antonio de Gorbea e Ignacio Domeyko, a quien califica de "ejemplo de sabio y varón" (1972, p. 194). Los científicos representarían la avanzada de la humanidad en un proceso evolutivo que, si bien se refleja en la evolución biológica descrita por Darwin, no se agota en esta, sino que se enmarca en una concepción general de la evolución como un proceso predestinado, por voluntad divina, a generar la inteligencia que buscará unirse finalmente al orden cósmico.

En este punto, Aldunate es deudor confeso del pensamiento del sacerdote jesuita Pierre Teilhard de Chardin, a quien considera "profeta de la Ciencia religiosa y la Religión científica" (1982, p. 69), cuyos argumentos serían definitivos para sustentar una concepción teleológica de la evolución, con el ser humano instalado en su cúspide como una etapa a superar para la fusión definitiva entre creación y creador. La Teoría Heroica del desarrollo científico se complementa así con esta mirada providencialista, en la que la grandeza intelectual de los grandes héroes se explica por su capacidad de haber captado el devenir divino y haberse integrado a él, expresando algunos de sus rasgos en el lenguaje que le sería propio: las matemáticas. "Gracias a ellos [...] mensajeros de la vida, herramientas o recursos del programa universal, estamos mirando con más conciencia las estrellas y escuchamos una voz secreta venida desde el fondo de nosotros mismos que musita: 'No estamos solos'” (1977, p. 63). La posición de Arturo Aldunate respecto del rol de la ciencia en el desarrollo, comprendido como fenómeno económico y social, hasta el momento parece estar ausente, existiendo un vacío entre el nivel individual y el trascendente, salvado por saltos que grandes hombres hacen en nombre de la especie. Esta es la posición expresada, aun moderadamente, en un nivel explícito. En su libro El amenazante año 2000 (1975a) en donde los problemas que asoman en el horizonte de la época para el futuro cercano, como la sobrepoblación, guerras o contaminación, parecieran ser simples desajustes en este proceso evolutivo y necesario, por lo que su solución pasará por un dejar hacer a este orden que ya habría probado ser verdadero:

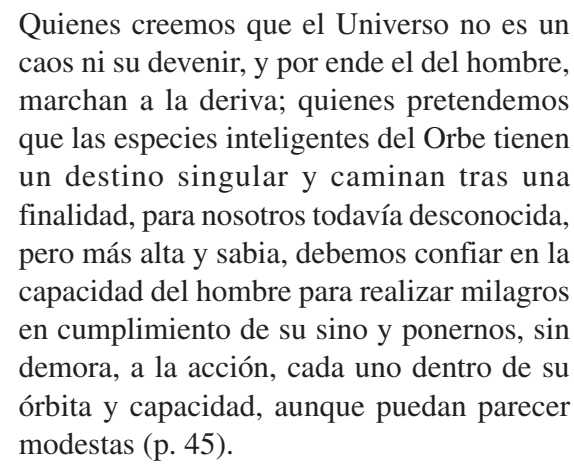

El orden social descrito de forma implícita aludiendo a la "órbita y capacidad" de cada cual podría incluso recordar a la célebre expresión de Karl Marx en su Crítica del Programa de Gotha "¡De cada cual, según sus capacidades; a cada cual según sus necesidades!” (p. 662), confusión posible que el autor cuida de aclarar, en esta obra, de forma metafórica:

las personalidades que sobresalen del nivel medio, son flores y frutos de los "árboles hombres"; si algunos equivocaron su conducta, si algunos frutos fueron dañinos o estériles, no es razón para esterilizar el bosque extirpando o destruyendo todos los brotes portadores de los gérmenes de nuevos individuos o de más encumbradas frondas. De este modo terminaríamos en el mismo funesto presagio de los pesimistas: la extinción del hombre o su asimilación a los himenópteros sociales (1975a, p. 212).

Un orden social armónico requiere el reconocimiento de jerarquías, como las que expone la ciencia con su historia de héroes, a riesgo de la desaparición o la deshumanización forzosa comparable al igualitarismo propio de un panal de abejas. Este orden, sin embargo, no es universal, sino que, como ya advertía la inspiración arielista, debe situarse en las características propias de la sociedad, en este caso, la chilena. Una exposición más profunda, aunque oscurecida por el estilo metafórico, se encuentra en la publicación Mensaje del Mundo Verde publicado en 1976, cuya relevancia para este análisis radica en que se trata de un escrito pensado como material de apoyo a niños de educación primaria. Aldunate toma narrativamente 
la voz de los vegetales endémicos amenazados por el progreso que advierten al lector de los peligros que enfrenta la civilización, pero también de sus potenciales teleológicos y divinos transversales a su obra. Para situar geográficamente el mensaje, inicia aludiendo al pueblo mapuche:

\begin{abstract}
Va el mensaje desde estas tierras de Arauco, acaso, porque aquí vivió (y aún vive) un pueblo de asombrosa bravura, altivo y libertario, respetuoso y enamorado de sus gigantescas, recias y hermosas catedrales de madera y follaje, y cuya veneración por el árbol lo llevó a incorporar en su liturgia religiosa al canelo aromoso, como "árbol sagrado". Sus hojas convertidas en símbolo de ventura lo acompañaron y aún lo acompañan en sus victorias y desastres, en sus alegrías y pesadumbres (p. 3).
\end{abstract}

Destaca del pueblo mapuche, no mencionado directamente, una relación "religiosa" con el entorno, que contrasta con el peligroso olvido que la modernidad ha hecho de este vínculo: "contrariamente a los hombres del sur, vuestros antepasados y mayores del "mundo civilizado", arrogantes por su habilidad para dominar a la naturaleza de su "morada cósmica" (p. 4). Resulta llamativo, además, que los potenciales destinatarios se asuman como descendientes de europeos, sin considerar la realidad antropológica y cultural del mestizaje, situándose el discurso de Aldunate en el tipo de pensamiento identificado con Ariel, pero ya no solo según las coordenadas de Rodó, sino también como una abstracción europeizada, según la relectura de Roberto Fernández Retamar (2005). Continuando con la exposición del pensamiento de Teilhard de Chardin que ha hecho propio, Aldunate reitera la dicotomía ya expuesta entre la realización de un plan divino preexistente y una extinción que lo frustra por haber insistido en desconocer las jerarquías naturales destinadas a comandarlo: "La vida, en cambio, y con mayor pujanza la vida inteligente, se opone a este proceso de igualación inerte; organiza, crea disimetrías y ante probabilidades, se encabrita frente al rasero de la igualdad" (p. 12). Finalizando su vocería literaria del reino vegetal, Aldunate enfatiza el rol de las ciencias -homologada a la razón- en la educación, no por sus utilidades ya largamente condenadas cuando se vuelven un fin primordial, sino como una actividad creativa valiosa en sí misma:
Las criaturas, los niños, cada niño, el material humano más dúctil y moldeable, apenas alcanzado el uso de razón, debe aprender, junto con los primeros signos de la expresión gráfica, la generosa, fraternal y constructiva historia del reino vegetal, creado para darle a nuestra residencia astral vida, belleza, armonía, amor y paz. En la Escuela y el Hogar, el plantar, alimentar y cuidar un árbol o una flor, debe convertirse en algo como cantar, reír o jugar; en una fiesta, en un ritual del espíritu (p. 13).

El foco, hasta ahora ausente, en una realidad local, se hace aún más explícito y de forma excepcional en el libro Chile mira hacia las estrellas (1975b). Si bien el libro busca ser una historia especializada de la astronomía en Chile (p. 11), el autor considera necesario dedicar casi cien páginas, de 265 , a realizar un resumen de las condiciones geográficas de Chile, así como los hitos más relevantes de su historia. Dentro de la descripción geográfica, aparece un apartado dedicado a la "composición racial" del país, aceptando la existencia de un mestizaje extendido, aunque con características peculiares: "la llegada de conquistadores europeos, godos de ascendencia guerrera en su mayor parte, sin mujeres de su raza, inició muy pronto un mestizaje" (p. 27). La evidencia para una afirmación tan general resulta ser Raza Chilena de Nicolás Palacios (1918), de donde además suscribe que

La buena conformación física de la mayor parte de las razas indígenas autóctonas incorporadas al conjunto, así como la carencia de asiáticos y negros, fue formando, con la indudable influencia de una naturaleza fuerte y vigente, lo que don Nicolás Palacios llamó [...] una población que [...] tiene una unidad nacional y espiritual singular" (pp. 29-30).

La unidad "nacional y espiritual" será el fundamento no solo de la historia científica de Chile en el orden teleológico cósmico, asignándole al país, por su geografía, su especificidad astronómica ${ }^{8}$, sino que, además, la "composición racial" implicará necesariamente "un pueblo modesto pero orgulloso de su nacionalidad, de su independencia, de su libertad" (p. 31), factor común a la historia de Chile resumida por Aldunate en la primera parte del libro. Ya en tiempos contemporáneos, extiende la explicación racialista que Palacios intentó dar al triunfo chileno en la Guerra del Pacífico, ahora al 
fallido gobierno de la Unidad Popular y el posterior golpe de Estado:

El reciente y rotundo fracaso de quienes intentaron introducir en el país conceptos, ideologías y costumbres ajenos a su idiosincrasia y el repudio general de toda la ciudadanía a la pretendida incorporación de extranjeros recién llegados al manejo del país y de sus más caras instituciones, son pruebas irrecusables de la reciedumbre de su nacionalidad y de su índole libertaria. Olvidaron los marxistas que Chile no es un pueblo tropical y que, en cambio, sigue estando formado, sin aspavientos, por una raza sobria, pero que, como lo cantara Ercilla, "no ha sido por rey jamás regida ni a extranjero dominio sometida" (p. 31).

Explicaciones más convencionales, es decir, fundándose en las razones económicas y políticas de la crisis, son expuestas cediendo largamente la palabra a Arturo Fontaine y su crónica en $E l$ Mercurio, reproducida de forma íntegra, así como declaraciones de Enrique Ortúzar, presidente de la Comisión de Reforma Constitucional. Aldunate retoma la palabra para incorporar tenuemente la variable geopolítica de la Guerra Fría, acusando la influencia imperialista de la URSS durante la UP y tras el golpe como propagadora de "versiones calumniosas" (p. 94), y el rol de la Junta como "reserva moral", imagen identitaria vigente en las FF.AA. (Garay, 2014). Arturo Aldunate relata que "el pueblo sencillo", ese compuesto de araucanogóticos y siguiendo su espíritu libertario, confía plenamente en la dictadura: "[1]as aflicciones pasadas y la confianza que inspira la honradez de los actuales gobernantes son factores que provocan el entusiasta afecto hacia la Junta, pese a que la política económica ha tenido que ser dura para muchos bolsillos modestos" (p. 111). Esta inusual introducción a un libro de historia de la astronomía antecede por un año la recepción del Premio Nacional de Literatura, que fue saludado en forma inédita por un jefe de Estado, para el caso, Augusto Pinochet ${ }^{9}$. La afinidad de la obra de Aldunate con la dictadura por medio de un marcado anticomunismo, sin embargo, no será completa, al considerar los aspectos económicos como secundarios e instrumentales respecto de las premisas metafísicas que ya se han expuesto. Exposiciones posteriores referidas a la Unión Soviética, muestran que Arturo Aldunate no tenía un rechazo al comunismo bajo aspectos que, ligeramente, podríamos llamar "epistémicos" o "gnoseológicos", es decir, respecto de si era o no un sistema utópico, irrealizable, o que generara más problemas de los que podía resolver. Por el contrario, en los aspectos pragmáticos reconoce a la URSS la capacidad de planificación y gestión, situación comprensible debido a la primacía que el autor da a la astronomía y la exploración espacial como ciencias fundamentales:

El Partido Comunista, rector e impulsor de los programas y de toda acción soviética, busca logros a corto plazo y de efectiva ayuda para su pretendida hegemonía en el planeta. Quien no reconozca esta realidad hoy día tan ostensible, está ciego de total ceguera. Los Estados Unidos, absorbidos igualmente por un materialismo utilitario individualista más que filosófico, buscan también logros materiales; pero gran parte de su pueblo, de sus gobernantes y hombres de ciencia, creen en la trascendencia de la aventura porque creen en la trascendencia del hombre; creen que la especie humana no termina su misión con la muerte de sus componentes; tienen fe en que, por sobre su acontecer, existe una teleología, una finalidad establecida por un Supremo Poder, con Omnipotente Inteligencia (1977, p. 250).

Ante la aparente equivalencia en logros técnicos, la URSS es rechazada solo por su matriz filosófica marxista, y su correspondiente igualitarismo y materialismo, negadores tanto de la teleología cósmica ${ }^{10}$ como de las jerarquías naturales que, manifiestas en mentes prodigiosas, guían a la totalidad de la especie a cumplir con un destino prescrito desde la eternidad anterior a su existencia. El rechazo al marxismo, como acto de fe en su sentido estricto, permite que la confrontación de los esquemas generales con la especificidad de la realidad resulte en una moderación del posicionamiento político, abriéndose incluso a valorar rasgos de la sociedad soviética. Dice Aldunate tras un viaje a Rusia:

Es otro mundo con conceptos diferentes, que no podemos juzgar con ligereza. Viajé solo a Rusia. Viví en un hotel modesto, sin hablar una palabra de ruso. Vi un pueblo vestido sin elegancia, es muy cierto, pero vestido, con educación para sus hijos. El título que allá abre todas las puertas es el de profesor, el universitario, el científico. El respeto hacia la gente que piensa es impresionante. Mi encuentro con los 
cerebros científicos y filosóficos me permitió concluir que son universales, no tienen fronteras políticas, integran una hermandad con espíritu constructivo de crítica, que aspiran a ver la humanidad, vivir en paz. ¡Lástima que ellos (los científicos y filósofos) ocupen solo el tercer lugar entre los hombres que gobiernan el mundo! ¡Antes están los políticos y militares! (cit. en Díaz, 1987, p. 970).

Con este antecedente, el rechazo vehemente de Aldunate a la Unidad Popular puede especificarse como la oposición al marxismo como ideología materialista e igualitarista, en tanto se opone a la "unidad espiritual" considerada propia de la raza chilena. En la URSS, pareciera que la implantación efectiva del marxismo ha excluido, al menos de momento, algunas de sus amenazas, conservando uno de los rasgos de la actividad científica que sería un valor cultural y moral por sí mismo para la sociedad: la búsqueda de una verdad universal, superior a los conflictos e intereses nacionales, y la necesaria división del trabajo que le otorgaría al científico una posición dirigente en el espacio intelectual, aunque todavía supeditada al poder político y militar.

La apelación a las ciencias como mecanismo de autoridad más allá de los problemas que buscan explicar, predecir y modelar, no es problemática cuando no está orientada a una visión religiosa del mundo, sino incompleta, pues al menos mantiene en pie la posibilidad de establecer un orden social cuyas jerarquías guíen el destino de la especie. Para Aldunate, el orden trascendente es simplemente innegable, y el desconocimiento que propicia el materialismo es tan solo una pausa en los inexorables peldaños del tiempo, que inevitablemente seguirá su marcha.

\section{CONCLUSIONES}

La obra de Arturo Aldunate Philips ha recibido atención como referencia para información acerca de la historia de la astronomía en Chile (Leyton, 2014; 2016), por su contenido religioso (Schmidt, 2015) y por su adscripción literaria debido a su formato ensayístico (Montes, 1982). En este artículo se ha propuesto abordarla desde los estudios de las ideas, identificando un cientificismo que se adosa a otras entidades eidéticas, como son el arielismo, el nacionalismo y la "religiosidad cósmica" de Teilhard de Chardin. Entre los usos posibles, resalta una visión del desarrollo que omite especificidades políticas y económicas en favor de una mejora que será tanto espiritual como universal, aunque determinada por los factores particulares de cada región, siendo para el caso chileno los que se insinúan por una asumida herencia racial y la ubicación geográfica. A un nivel político, el pensamiento de Aldunate puede ubicarse en la derecha, aunque con algunas precisiones. Si bien su nacionalismo se apoya en el racialismo de Nicolás Palacios, una de las principales fuentes de movimientos nacionalistas de la primera mitad del siglo XX, como Acción Nacional o el Movimiento Nacional Socialista, se diferencia en un aspecto crucial como es el foco de estos grupos en la industrialización y el desarrollo económico como mecanismo para resolver la "cuestión social", coherente con la autoidentificación del MNS como "de izquierda" (Correa, 2005, pp. 67). Más afín a Aldunate resulta el socialcristianismo de la década del 40 , visto por sus seguidores como "la única solución alternativa al marxismo para enfrentar los problemas sociales, económicos y políticos. Lo caracterizaban como lo espiritual confrontado al materialismo" (p. 144), comprendiendo por materialismo el énfasis mercantil que también incluía al liberalismo. La derecha en la que podríamos situar a Aldunate, por esta razón, corresponde a una de las vertientes que quedarían relegadas tras la implantación del neoliberalismo y la Constitución de 1980, deudora del pensamiento de Jaime Guzmán y su superación del corporativismo y el comunitarismo por el realismo pragmático e individualista (Cristi, 2011).

El arielismo, que "reivindicó una forma propia de ser, influida por lo latino, por lo espiritual, por el vitalismo y la libertad" (Devés, 2000, p. 91), en Aldunate cobra forma asignándole a la ciencia el rol vitalista como homólogo de la razón, facultad trascendente y propia de una creatura hecha a imagen y semejanza divina. Será comprensible, por ello, que Aldunate entienda por "ciencia" el conjunto de conocimientos de la física, la astronomía o incluso la naciente cibernética, debido a su lenguaje matemático, ignorando disciplinas como la geología o la medicina, y mencionando la biología más como metáfora de las ideas espiritualistas y teleológicas de Teilhard de Chardin que como una ciencia autónoma. Las matemáticas, como lenguaje racional por excelencia, son homologadas con la realidad misma: "[1]os números naturales, en efecto, y las constantes universales, son como el anclaje de la urdiembre que sostiene la realidad, esta realidad relativa y cambiante, producto de una 
interpretación humana de las manifestaciones del cosmos" (Aldunate, 1958, p. 111). Si es patente el cientificismo de Aldunate al considerar a las ciencias como la actividad humana por excelencia, reservada a los grandes héroes, su categoría de ciencia se reduce asimismo a un fundacionalismo matemático, cuya base última es metafísica, como recuerda el llamado a recuperar la filosofía natural de Roberto Unger y Lee Smolin. Este salto fue advertido, al menos, tras su última publicación, Luz, sombra de Dios, como se observa en la crítica que Ignacio Valente le realiza en El Mercurio: "él quiere hacer hablar de Dios a las ciencias actuales sin el menor asomo de elaboración filosófica, sin los elementos lógicos y metafísicos del caso; va de la astrofísica a Dios directamente" (cit. en Díaz, 1987, p. 993). La filosofía de Aldunate aparece espontáneamente como premisas no problematizadas ni puestas en diálogo con las objeciones o reelaboraciones propias de la tradición filosófica, limitando severamente el objetivo que el autor impuso para su obra: ser un puente entre las humanidades y las ciencias, una superación de una dicotomía cultural en favor de una verdad trascendente que la engloba. Insiste Valente: "[d]ebo subrayar el vacío filosófico de un ensayo que necesitaba imperiosamente de la filosofía para cumplir con su objetivo declarado esto es, un humanismo científico" (p. 994).

El vacío filosófico se representa con la ausencia ya mencionada de otras ciencias, que se vuelve aún más patente al incluir en esta clasificación a las ciencias sociales, como la antropología o la sociología. La persistencia en clasificaciones raciales como factor determinante para el destino cultural de la nación, más allá de las posiciones políticas, constituye un desfase de décadas con el consenso científico de que la categoría "raza" es un constructo social, y que sus pretendidos fundamentos biológicos resultaron espurios (Montagu, 1998). Una explicación para este anacronismo puede ser de índole generacional: nacido en 1902, y de formación humanística autodidacta, Arturo Aldunate creció en una época en donde "lo social" se abordaba preferentemente desde la vocación literaria, poética y ensayística, como indica su identificación con el arielismo de José Rodó, a diferencia de lo que ocurrirá a mediados de siglo en América Latina, con un creciente desarrollo de las ciencias sociales y su respectivo enfoque técnico, aun considerando sus ineludibles problemas filosóficos (Devés, 2000). La obra de Aldunate puede agruparse entonces como una tardía manifestación del "arielismo de derecha" (p. 98) en la medida en que opta por un foco más culturalista que social, entendiendo el primero como un vitalismo espiritualismo -en este caso, identificado con la ciencia- y el segundo como la lucha política.

La excepcional mención de Aldunate a hechos políticos contingentes, como su condena a la Unidad Popular y su apoyo al golpe de Estado y su posterior dictadura, se acercan más a la restauración de un orden perdido que la adhesión a un proyecto particular. Un dejar hacer que es anterior, en temporalidad y fundamentos, al neoliberalismo, cuya metáfora de la "mano invisible" posee raíces cristianas: there is the idea of a kind of "providence" and self-organization which is traceable to Calvin. The other idea of harnessing and transforming passions and vices into something constructive that works toward the general welfare [...] is traceable to Augustine ${ }^{11}$ (Wariboko, 2008, p. 34).

A partir de los antecedentes expuestos resulta plausible plantear que la obra ensayística de Arturo Aldunate Philips constituye un caso de cientificismo usado para validar la más espiritualista y nacionalista de las versiones del arielismo, siendo ya por ello una formulación original respecto del cientificismo entendido como una ideología colonialista emanada del centro. Aun cuando los objetivos de Aldunate puedan ser la homogeneización global en nombre de la ciencia, esta ocurre desde un lugar particular, reafirmando la posición expresada por Leopoldo Zea: "[e]l Ser, Dios, etc. aunque temas válidos para cualquier hombre, serán temas cuya solución se daría desde un punto de vista americano [...]no podríamos decir lo que son para todo hombre, sino lo que son para nosotros, hombres de América" (1988, p. 199). El alcance del cientificismo, por tanto, resulta estar circunscrito al uso en favor o en contra de otras entidades eidéticas, en este caso, a favor de un espiritualismo de vocación latinoamericana y a una visión providencial y teleológica de la evolución; y en contra del materialismo y el igualitarismo. El materialismo nos clausuraría el acceso a esa verdad trascendente que, para Aldunate, insinúan las propias ciencias dándoles así una autoridad incontestable, y el igualitarismo nos haría ignorar tanto las jerarquías necesarias dentro de la sociedad como las diferencias entre sociedades, que impiden la implantación de sistemas políticos y económicos pensados en y para tierras lejanas. De ello se encargará la voluntad divina en su devenir 
solo disponible a mentes privilegiadas, las que, si no encuentran trabas artificiosas, podrían guiar a toda la especie en su trayecto ascendente. La ciencia, como se ha visto, también ha podido usarse como argumento de autoridad para fines espirituales y emancipadores, aun cuando las coordenadas políticas de esta emancipación hoy nos parezcan obsoletas.

Arturo Aldunate puede incluirse así en la categoría de quienes sostienen que no hay tal cosa como una confianza exagerada en las ciencias, entendiendo sus resultados y métodos, aplicados a la totalidad del conocimiento. En este caso, el cientificismo se usa para intentar justificar mediante la coherencia y éxito de teorías físicas, cosmológicas, así como avances cibernéticos, una metafísica cristiana que implica además postulados éticos que, finalmente, se pueden traducir en posiciones políticas, si bien no explícitamente propositivas, sí claramente limitantes respecto de qué ideologías no se deben permitir. El pensamiento científico de Aldunate en términos de "filosofía natural" -según la acepción propuesta en un inicio- resulta menos interesante como contenido que como representación de las distintas posibilidades que abre el cientificismo, sugiriendo que este concepto no debe asociarse necesariamente a fines ideológicos o filosóficos específicos, sino que puede ser instrumentalizado para objetivos aparentemente ajenos. 


\section{BIBLIOGRAFÍA}

Aldunate, A. (1953). Al encuentro del hombre. Buenos Aires: Editorial Guillermo Kraft Limitada.

Aldunate, A. (1956). Alberto Einstein. El hombre y el filósofo. Santiago de Chile: Ediciones de los Anales de la Universidad de Chile.

Aldunate, A. (1958). Quinta Dimensión. Santiago de Chile: Editorial Universitaria.

Aldunate, A. (1970). Universo Vivo. Barcelona: Editorial Pomaire.

Aldunate, A. (1975a). El amenazante año 2000. Santiago de Chile: Joaquín Almendros Editor.

Aldunate, A. (1975b). Chile mira hacia las estrellas. Santiago de Chile: Editora Gabriela Mistral.

Aldunate, A. (1976). Mensaje del Mundo Verde. Santiago de Chile: Editorial Universitaria.

Aldunate, A. (1977). Los Caballos Azules. Valparaíso: Ediciones Universitarias de Valparaíso.

Aldunate, A. (1981). Luz, sombra de Dios. Santiago de Chile: Editorial Universitaria.

Aldunate, E. (1981). Arturo Aldunate Philips (1905-1985). Premio Nacional de Literatura 1976. En A. Aldunate, Luz sombra de Dios (pp. 13-14). Santiago de Chile: Editorial Universitaria.

Arpini, A. (2004). Posiciones en conflicto: latinoamericanismo-panamericanismo. En Biagini, H. y Roig, A. (Dir.) El pensamiento alternativo en la Argentina del siglo XX. Tomo I. Identidad, utopía, integración (1900-1930) (pp. 31-50). Buenos Aires: Biblos.

Bidegaín, A. M. (1992). La ideología cientificista y la implantación de la dinámica desarrollo-contradesarrollo. En R. M. G Neves y A. M. Bidegaín, América Latina al descubierto: más allá de los 500 años, el reto de la solidaridad (pp. 133-161). Madrid: IEPALA.

Badran, M. (2009). Feminism in Islam: Secular and Religious Convergences. Oxford: Oneworld.

Blasco, I. (2006). Feminismo católico: una propuesta de ciudadanía femenina en la España de los años veinte. En I. Morant, (Dir.), Historia de las Mujeres en España y América Latina IV: Del siglo XX a los umbrales del XXI (pp. 55-75). Madrid: Cátedra.

Bunge, M. (2017). Elogio del cientificismo. En Andrade, G. (Ed.) Elogio del cientificismo (pp. 13-30). Pamplona: Editorial Laetoli.

Correa, S. (2016). Con las riendas del poder. La derecha chilena en el siglo XX. Santiago de Chile: Debolsillo.

Cristi, R. (2011). El pensamiento político de Jaime Guzmán. Una biografía intelectual. Santiago de Chile: LOM.

De Miguel, A. (1995). Feminismos. En Amorós, C. (Ed.), 10 palabras clave sobre mujer (pp. 217-256). Pamplona: Verbo Divino.

Devés, E. (2000). El pensamiento latinoamericano en el siglo XX. Entre la modernización y la identidad. Tomo I, Del Ariel de Rodó a la CEPAL (1900-1950). Buenos Aires: Biblos.

Devés, E. y Kozel, A. (2017). Estudios Eidéticos. Una conversación desde el Sur sobre la vida de las ideas y la reconfiguración de un espacio disciplinar. San Martín: Teseo.
Díaz, Miguel Ángel (1987). Premios Nacionales de Literatura. Tomo V. Santiago de Chile: s.e.

Dussel, E. (1980). Filosofía de la liberación. Bogotá: Universidad Santo Tomás.

Estenssoro, F. (2006). El concepto de ideología. Hermenéutica Intercultural: Revista de Filosofía, (15), 97-11.

Fernández, R. (2005). Todo Calibán. Bogotá: Publicaciones ILSA.

Garay, C. (2014). Entre la espada y la pared. Allende y los militares 1970-1973. Santiago de Chile: Editorial Bicentenario.

Hook, S. (1955). Science and Dialectical Materialism. En Congress for Cultural Freedom (Eds.), Science and Freedom: The Proceedings of a Conference Convened by the Congress for Cultural Freedom and Held in Hamburg on July 23rd-26th, 1953 (pp. 182-196). Boston: Beacon Press.

Leyton, P. (2014). Andrés Bello y la Cosmografía: la literatura científica desde la perspectiva de la historia cultural de la ciencia. Cuadernos de Historia Cultural, 3, 77-108.

Leyton, P. (2016) Espectáculo solar y su imagen pública. La participación chilena en el eclipse de 1853 en Ica, Perú, y su utilización política. En Correa, M. J., Vetö, S. y Kottow, A. (Eds.), Ciencia y espectáculo. Cirulación de saberes científicos en América Latina, siglos XIX y XX (pp. 151-172). Santiago de Chile: Ocho Libros.

Marx, K. (2012). Crítica del Programa de Gotha. En K. Marx, Obras, (pp. 651-675). Madrid: Gredos.

Merton, R. K. (1973). The Sociology of Science. Theoretical and Empirical Investigations. Chicago: The University of Chicago Press.

Montagu, A. (1998). Man's Most Dangerous Myth. The Fallacy of Race. Walnut Creek: Altamira Press.

Montes, H. (1982). Prólogo. En Luz sombra de Dios (pp. 15-23). Santiago de Chile: Editorial Universitaria.

Palacios, N. (1918). Raza Chilena. Santiago de Chile: Imprenta Universitaria.

Pigliucci, M. (2018). Scientism and pseudoscience. In defense of demarcation projects. En Boudry, M. y Pigliucci, M. (Eds.) Science Unlimited? The Challenges of Scientism (p. 185-203). Chicago: The University of Chicago Press.

Raynaud, D. (2017). Cientificismo metodológico. En Andrade, G. (Ed.) Elogio del cientificismo (pp. 53-76). Pamplona: Editorial Laetoli.

Schmidt, C. (2015). La ciencia: un camino hacia Dios para Arturo Aldunate Philips. Estudios. Filosofía. Historia. Letras, 115, 175-198.

Schöttler, P. (2017). Cientificismo. Historia de un concepto difícil. En Andrade, G. (Ed.) Elogio del cientificismo (pp. 3152). Pamplona: Editorial Laetoli.

Thorndike, L. (1905). The Place of Magic in the Intellectual History of Europe. Nueva York: The Columbia University Press.

Unger, R. M. y Smolin, L. (2014). The Singular Universe and the Reality of Time. Cambridge: Cambridge University Press.

Villoro, L. (1996). Creer, saber, conocer. México D. F.: Siglo XXI. 
Wariboko, N. (2008). God and Money. A Theology of Money in a Globalizing World. Plymouth: Lexington Books.

Wootton, D. (2015). The Invention of Science. Nueva York: Harper.
Zea, L. (1988) En torno a una filosofía latinoamericana. En Gracia, J. y Jaksic, I., (Eds.), Filosofía e identidad cultural en América Latina (pp. 185-208). Caracas: Monte Ávila Editores. 


\section{NOTAS}

1 "Una creciente y perniciosa connotación negativa no razonable, un uso simplista de cientificismo como un epíteto para ser lanzado a las ideas que a uno no le gustan en medio de una discusión". Traducción propia.

2 "No hay tal cosa como una confianza exagerada en la eficacia de los métodos de la ciencia natural aplicados a todas las áreas de investigación". Traducción del autor.

3 Se entenderá el término "eidético" en su acepción de "idea", sin considerar el desarrollo que ha tenido como concepto, por ejemplo, en la fenomenología. Por "estudios eidéticos" se entenderá "estudio sistemático de las ideas", debido a que "ideología" el término propuesto para este fin por Destutt de Tracy en 1796 (Estenssoro 2006) ha adquirido una historia propia e ineludible.

4 Otras clasificaciones posibles de las entidades eidéticas son:

- Según código geneidético (familia).

- Según función: identitaria/centralitaria, disciplinadora/de rebelión, cosmopolita/nacionalista, cohesiva/confrontativa, expansionista/rechazo o expulsión del invasor

- Según grado de complejidad (cantidad de ideas)

- Según grado de agencia: cuasinulo, bajo, alto, muy alto (Devés y Kozel 2017, p. 329-31).

5 "Actualmente, la filosofía natural no ha desaparecido completamente. Vive disfrazada. Los científicos escriben libros de divulgación, para el público general y educado, buscando hacer accesibles sus ideas acerca de la ciencia que practican a los no científicos. Usan estos libros para especular acerca del significado más amplio de sus descubrimientos para nuestra comprensión del universo y nuestro lugar dentro de él [...] Los libros de divulgación se han vuelto una forma secreta de un género olvidado, una criptofilosofía natural”. Traducción del autor.

6 "La interpretación se influencia comúnmente con preconcepciones metafísicas, especialmente ontologías supraempíricas -consideraciones acerca del tipo de objetos que existen en el dominio abordado por la ciencia-. Estas consideraciones forman una parte ineludible de la teorización científica". Traducción del autor.

$7 \quad H e$ preferido el término "eidético" en vez de "ideológico" para denotar una relación de influencia, sin pretender establecer un juicio de verdad, como ocurriría con el término "ideología" en la tradición marxista, ni tampoco asignarle una pretensión política explícita, como ocurre en la acepción común, por ejemplo, en la obra de Althusser (Estenssoro).

8 Dice Aldunate al respecto: "este largo barco de más de 7 mil millas parece haber nacido con la vocación de "mirar hacia las estrellas' y seguramente por ese destino que es posible realizar desde toda su larga cubierta, su pueblo prendió a su emblema patrio sobre cielo azul una estrella de plata de proporciones áureas" (cit. en Díaz, 1987, p. 989).

9 Dijo Augusto Pinochet a Arturo Aldunate: "Tan merecido galardón viene a coronar con justicia una vasta trayectoria dedicada con esfuerzo y tesón, destinada a profundizar en el apasionante devenir de las ciencias, lo que permitiría también que se reconozca en él a todos aquellos que como Ud. construyen día a día nuestra cultura por el camino de las letras" (cit. en Díaz, 1987, p. 980).

10 Existen lecturas del marxismo-leninismo que acusan una persistencia de una teleología universal, como la efectuada desde la tradición pragmatista (Hook, 1955). La incompatibilidad entre marxismo y teleología cósmica se refiere a la reconstrucción que he realizado de los argumentos de Arturo Aldunate.

11 "Existe la idea de un tipo de 'providencia' y autoorganización que es rastreable hasta Calvino. La otra idea de aprovechar y transformar las pasiones y vicios en algo constructivo que funciona para el bienestar general [...] es rastreable hasta Agustín". Traducción del autor. 